\title{
Gender and policy persuasion
}

\author{
Georgia Anderson-Nilsson and Amanda Clayton* \\ Department of Political Science, Vanderbilt University, Nashville, TN, USA \\ ${ }^{\star}$ Corresponding author. Email: amanda.clayton@vanderbilt.edu
}

(Received 30 March 2020; revised 21 September 2020; accepted 29 September 2020; first published online 15 February 2021)

\begin{abstract}
Are policy arguments more or less persuasive when they are made by female politicians? Using a diverse sample of American respondents, we conduct a survey experiment which randomly varies the gender associated with two co-partisan candidates across four policy debates. We find strong effects contingent on respondent partisanship and gender, most notably on the issue of access to birth control. On this issue, regardless of the candidate's stance, Democratic respondents, particularly Democratic men, are much more likely to agree with the female candidate. Conversely, Republican respondents, particularly Republican women, are much more likely to agree with the male candidate. We discuss the implications of our findings for the meaning of gender as a heuristic in a highly partisan environment.
\end{abstract}

Keywords: American politics; experimental research; gender and politics

\section{Introduction}

The ability to persuade is a fundamental political skill. Both as candidates and as elected officials, politicians try to influence the preferences of others to accomplish their electoral or policy goals. On the campaign trail, candidates attempt to persuade potential voters of their fitness for the job. Once in office, politicians use their skills of persuasion during policy debates, an activity frequent in all deliberative bodies from the floors of the House and Senate to town hall meetings. Yet, persuasiveness rarely derives solely from the merits of proffered arguments, but rather by "who says what, in which channel, to whom, and with what effect" (Lasswell, 1948, 37). Importantly, various aspects of a speaker's identity can strongly influence his or her persuasiveness. For instance, Americans are more likely to agree with those with whom they share a salient identity, or with individuals about whom they already have positive opinions (Druckman and Lupia, 2016).

In this study, we focus on one particular aspect of identity that may condition the effectiveness of political persuasion: the speaker's gender. We ask whether and under which circumstances a politician's gender affects his or her success at political persuasion. We isolate the effect of gender on persuasiveness through a survey experiment with a large and diverse sample of American respondents. Our experiment exposes respondents to recorded policy debates in which a male and a female candidate from the same political party take opposing sides on an issue, randomly varying the position the speakers take. We investigate gender differences in perceived persuasiveness in one policy dimension that is nominally non-gendered (tourism), and across three policy domains that previous research suggests are highly gendered: national security, children's health, and access to birth control. We ask respondents to choose which of the two speakers they agree with, and to evaluate how much expertise they believe the speaker has on the topic under debate.

We find evidence that male and female speakers from the same party are evaluated differently when making identical policy arguments. However, these evaluative differences are highly 
contingent on the policy under discussion as well as respondent gender and partisanship. The largest and most consistent evaluative differences emerge on the issue of access to birth control. On average, Democrats are more likely to agree with the female candidate regardless of the stance she takes, whereas Republicans are consistently more supportive of the male candidate, regardless of the stance he takes. Moreover, for Democrats, support for the female speaker's position is particularly strong among Democratic men. The inverse is true among Republican respondents: support for the male speaker's position on birth control access is particularly strong among Republican women.

Our findings suggest that gender conditions political persuasion on topics related to women's rights, but in opposing ways for men and women in both major parties. We did not anticipate our findings $a$ priori, and thus treat our interpretations as necessarily speculative. Yet, we suggest our results speak to the varying ways gender serves as a heuristic to different types of voters in a highly polarized environment. We speculate that Democratic men are the group most persuaded by the female speaker because men, on average, tend to have less crystallized views on issues pertaining to women's reproductive health. Democratic men in particular may be more likely to rely on a woman's argument to make the "correct" policy choice (see Clayton et al., 2019). In contrast, Democratic women's views on the topic are likely more fixed and less able to be swayed by either speaker.

We also find that Republican women are the group most convinced by the male speaker on the issue of birth control, regardless of the position he takes. We believe this finding supports recent studies that documents the growing mistrust between Democratic women and Republican women (see, e.g., Klar, 2018). Our survey told respondents that the candidates were from the same party, but not which party they belonged to. We speculate Republican women may have assumed the female speaker was a Democrat and may have registered their mistrust by agreeing with the male (Democratic) speaker instead. Furthermore, the issue of birth control may have cued Republican women respondents to think about reproductive rights more broadly, an issue on which they tend to hold more conservative views and tend to prioritize more in elections compared to Republican men (NPR/PBS NewsHour/Marist Poll, 2019). Because voters tend to assume female candidates are more liberal than male candidates (Dolan, 2004; Sanbonmatsu and Dolan, 2009), Republican women may have inferred that the male candidate was more conservative on the issue of reproductive rights and thus more likely to hold views congruent with their own. Although our interpretations are speculative, we hope future research will build on these findings to further test how gender conditions policy persuasion in a highly polarized environment.

\section{Gender, leadership, and persuasion: existing literature}

Previous research reveals the many ways female politicians face gendered campaign and legislative environments that may render them less persuasive to various audiences. Citizens may view women as less influential and less competent than men even when they hold objectively similar or even higher qualifications (Mendelberg et al., 2014; Madsen, 2019; Bauer, 2020). Female politicians may also have a more difficult time establishing credibility as policy experts in the first place (Ditonto et al., 2014). This body of research largely suggests that women face evaluative penalties when they occupy roles or engage in behaviors that are seen as traditionally masculine. Moreover, such gender biases appear particularly pronounced in issue areas that are traditionally associated with male traits or competencies. Voters tend to express strong preferences for male leaders under conditions of terrorist threat (Holman et al., 2016), and citizens tend to see women as having more expertise in stereotypical feminine policy realms, such as health and social welfare (Searles et al., 2017). Women also tend to perform better electorally when feminine policy issues are salient, whereas men perform better when masculine issues are salient (Kahn, 1994).

Our study also speaks to the considerable body of research that demonstrates the many ways women's authority is actively undermined. Women tend to be interrupted more often than men 
in deliberative settings, particularly when they are in the minority and when group decisions are made through majoritarian rather than consensus-based rules (Karpowitz et al., 2012; Mendelberg et al., 2014). Across the world, women are also more likely to occupy less prestigious and less powerful roles in government (Escobar-Lemmon and Taylor-Robinson, 2005; Krook and O’Brien, 2012), and are less likely to be acknowledged for their contributions to political debates (Clayton et al., 2014). As a result, women may adopt different legislative styles. Work from the US Congress suggests congresswomen display more consensus-oriented behavior than congressmen (Volden et al., 2013), a strategy that women may adopt precisely because they wield less individual power. Related to our study, if women are viewed as less persuasive, it may in part explain why they adopt less agentic leadership styles.

Our research brings together and advances study on gender stereotypes and political persuasion. Although past research indicates that men and women are seen as more competent in particular policy areas or preferred when certain issues are salient, we are not aware of any study in this vein that examines how voters evaluate gender differences in persuasiveness. Yet, we believe this is a particularly hard and important test for the existence of gender stereotypes. Rather than asking citizens who they would like to represent them in the future, we are asking respondents to evaluate the merits of one-time identical arguments. Any differences based on the speaker's gender reflect respondents' immediate evaluations of the speaker's credibility on a particular topic, rather than what the respondent thinks the politician might do in the future. Finally, past research in this area typically presents speakers and arguments in isolation from one another. This exposes respondents to one policy argument at a time rather than to the back-and-forth that typically accompanies political debate. Our research design enables us to examine how citizens respond to women when they actively and contentiously engage with a male speaker on different policy issues.

\section{Theory: gender and policy persuasion}

We ask whether and how a politician's gender conditions his or her ability to persuade voters across different policy domains. Previous research indicates that women may start at a general disadvantage in their ability to deliver persuasive arguments. Individuals tend to be most persuasive in contexts that fit well with salient aspects of their identity (Heilman, 2012). Gendered social role expectations typically cast men as strong, independent, and assertive, and women as nurturing, communal, and emotional. Because leadership roles are more agentic, they tend to be more readily and closely associated with men because they align with these stereotypical masculine traits (Eagly and Karau, 2002). Likely as a result, historically voters have tended to view men as more competent political leaders than women (Huddy and Terkildsen, 1993). Perceptions of women's lack of fit in leadership roles can lead to worse performance evaluations, even when their performance is objectively equal or better than that of men, and this effect tends to be strongest when the perceived lack of fit is greatest (Heilman, 2012). The congruity between leadership roles and masculinity could lead citizens to perceive men as more credible and therefore more persuasive.

Because gender stereotypes that cast women as warm and communal are both descriptive and prescriptive, women who violate these expectations tend to experience negative evaluative penalties. Relative to men, women tend to be punished disproportionately for engaging in negative campaigning (Krupnikov and Bauer, 2014), likely because women are expected to be more collaborative, cooperative, and fair than men (Cassese and Holman, 2018). Negative reactions toward female leaders are often stronger when women engage in stereotypical masculine behaviors (Heilman and Haynes, 2005). Consequently, women may be at a particular disadvantage in contexts of debate or argumentation, particularly when they make negative arguments. Because persuasive arguments tend to be most effective when they are positively valenced, the negative evaluative penalties incurred by women in leadership positions may also render them less 
persuasive. We thus hypothesize that men should be judged as more persuasive than women in making policy arguments in gender neutral policy areas.

Variations in policy context may also affect gender differences in perceived persuasiveness. Citizens may penalize women in realms gendered as male, such as national security and combating terrorism. This can occur for at least two reasons. First, as the literature above stresses, citizens tend to associate these types of policy realms with traits that are stereotyped as masculine, such as strong agentic leadership styles (Holman et al., 2016). Second, voters may assume that men have more expertise in these policy areas given that men are more likely than women to serve in the military. In this case, citizens may display a form of statistical discrimination, assuming that men are more likely to have a particular background or area of expertise than are women. We thus hypothesize that respondents will view men as more persuasive than women in male-gendered policy areas.

Voters tend to perceive women as having more expertise in stereotypical feminine policy realms, which may make citizens see women as more persuasive than men in these areas (Dolan, 2010). A similar logic applies here. First, if leadership in this area is viewed as more communal and consensus-based, citizens may view the issues themselves as more congruent with stereotypical female traits. Second, if voters assume women have more expertise in areas that are gendered female-for instance, on issues related to healthcare or family care-giving-voters may see women as more credible on these topics and as more qualified to fill leadership roles in these areas (e.g., Searles et al., 2017). We thus hypothesize that respondents will evaluate women as more persuasive than men in female-gendered policy areas.

Although certain issues are gendered as male or female due to social expectations and stereotypes about men's and women's behavior, there are also issues that directly pertain to the rights or welfare of women or men as distinct social groups. Therefore, we are also interested in differences in citizens' evaluations of male and female politicians on an issue that pertains to women's rights as women (see Beckwith, 2014, for a distinction between "women's issues" and "women's interests."). ${ }^{1}$ As we detail further below, we choose an issue related to women's reproductive health, namely whether oral contraceptives should be made available without a prescription or "over the counter." This issue area is distinct from the issues listed above because it affects women as women. Although men can certainly have expertise in this area (if they are doctors or nurses, for instance), the vast majority of women will have life experiences that lend them credibility in weighing in on policy debates about women's reproductive health. Second, although men are certainly affected by women's reproductive choices, it is women that typically disproportionately bear the effects of policy decisions in this area. We thus anticipate that citizens will view female politicians as more credible and as having more expertise in this area, which we expect will also grant them more persuasive ability. Thus, we hypothesize that respondents will evaluate women as more persuasive than men in issue areas directly pertaining to women's rights as a group.

Finally, we expect heterogeneous effects by respondent partisanship. Democratic and Republican voters evaluate candidate gender differently. Although women may actually experience an advantage due to their gender among Democratic voters, female candidates tend to experience a disadvantage among Republican voters (Dolan, 2004). This may be due to different attitudes held by Democratic and Republican voters: Democrats tend to place more importance on gender equality in government, whereas Republicans are likely to hold more traditional gender attitudes (Koch, 2000; Sanbonmatsu and Dolan, 2009). This may also be due to the strong ideological signal associated with gender in American politics, as women tend to be stereotyped both as more liberal than men and as more liberal than they actually are (Sanbonmatsu and Dolan, 2009). Moreover, past research studying the influence of gender and party cues on trait

\footnotetext{
${ }^{1}$ This distinction also fits with the conceptualization made by Iyengar et al. (1997) regarding "latent" versus "manifest" gender issues. The former pertains to issues that affect women's rights and interests as women, whereas the latter pertains to issues that evoke stereotypes about women's perceived strengths.
} 
evaluations indicates that party stereotypes can be more powerful than gender stereotypes (Sanbonmatsu and Dolan, 2009; Hayes, 2011). Finally, there is significant overlap between party and gender issue areas. Both Democrats and women are typically perceived as better at handling issues such as welfare, healthcare, and education, whereas Republicans and men tend to "own" issues such as security and the deficit (Meeks and Domke, 2016, 900). Thus, we hypothesize that Democratic respondents will tend to evaluate women as more persuasive and that Republican voters will tend to evaluate men as more persuasive across policy contexts. We further hypothesize that these differences will be most pronounced in gender-congruent policy areas.

\section{Data and methods}

We fielded our survey experiment in late September 2019. Our experimental design isolates the effect of candidate gender on the persuasiveness of a policy argument. To do this, we vary the gender associated with two candidates on either side of a political debate, randomly assigning the male or female candidate to different positions. Specifically, respondents listen to a recorded policy debate between two hypothetical candidates with the following instructions:

"This debate is between two candidates in a state primary election, Susan Miller and Brian Johnson. Both candidates belong to the same political party, but are expressing different viewpoints on this issue."

We chose the setting of state primaries for two reasons. First, because partisanship is such a strong predictor of candidate support, we anticipated that party would swamp respondents' evaluations of candidates from different parties. Second, if we did not include any mention of party, we were concerned that respondents would assume that the female candidate was a Democrat and that the male candidate was a Republican, given the dominance of men in the Republican party. ${ }^{2}$ Respondents then listen to a policy debate between these two hypothetical candidates through a voice recording that lasts about one and a half minutes. The debates are structured as follows: The first candidate takes a position and the second candidate responds with a different position. The first candidate then speaks again and the second candidate responds again. Importantly, we randomize which of the two positions the male and female candidates take. This allows us to compare how respondents evaluate the persuasiveness of the male versus the female candidate based on hearing exactly the same argument.

We signal candidate gender through name (Susan Miller versus Brian Johnson), the voice in the recording, and the associated picture of the candidate. The voice actors were instructed to maintain a neutral tone. We selected public domain photos associated with Brian Johnson and Susan Miller, which are the official photos of an actual male and female state legislator. Both photos are of middle-aged white legislators with similar facial expressions, dress, and affect. Both photos are well matched on perceived attractiveness, likability, competence, and age. ${ }^{3}$ We selected photos of white legislators because we feared that respondents would assume legislators of color belonged to the Democratic party. In the US House, 44 percent of Democratic members are nonwhite, whereas this describes only 5 percent of Republican members. We are thus aware that this limits the external validity of our study, as we can only speak to how voters evaluate men and women who belong to the historically dominant racial group. We hope future research examines how candidate race or ethnicity interacts with candidate gender as voters evaluate persuasiveness.

We selected three policy domains that previous research suggests are viewed as gendered: one in a stereotypical masculine policy area (national security), a stereotypical feminine policy area

\footnotetext{
${ }^{2}$ Women consist of 17 percent of Republican state legislative members and 41 percent of Democratic state legislative members.

${ }^{3}$ Matching was conducted based on a MTurk sample of 200 respondents who rated a total of approximately 150 images.
} 
(children's health), an area related to women's rights (access to over-the-counter birth control), and a relatively gender-neutral policy area (tourism) (on issue stereotypes see, e.g., Krook and O’Brien, 2012). For each policy debate, we construct similarly strong arguments on both sides. We also select issues on which respondents are unlikely to have strong prior stances, and those which are not part of current national partisan debates. On the issue of children's health, one candidate supports flu shots being made mandatory for all incoming kindergartners, whereas the other candidate supports flu shots being voluntary. On the issue of national security, one candidate proposes increasing funding to state and local law enforcement to combat terrorism whereas the other candidate proposes increasing funding to private organizations to achieve the same goal. For tourism, one candidate supports increasing the number of industry representatives on local tourism boards, whereas the other candidate opposes this. Finally, on the issue of women's reproductive health, one candidates supports birth control pills being made available over the counter, whereas the other candidate supports keeping the prescription requirement. In order to improve the experiment's mundane realism, we adapted our scripts from real policy debates. The complete texts from each issue are listed in the Supplementary Appendix. As an example, the text from the debate about over-the-counter birth control is as follows:

Position A: Birth control pills should be available over the counter. Making the pill available over the counter would have a variety of positive consequences. It would lower the number of unwanted pregnancies and lower teen pregnancy rates. Studies show that when teens have access to contraceptives, teen pregnancy rates drop significantly.

Position B: Birth control pills should not be available over the counter. Teen pregnancy rates are not likely to change if the pill is made available over-the-counter, as many teens do not know how to take the pill correctly. Requiring a prescription not only ensures they are instructed on proper use by a medical professional, but also encourages them to have additional screenings, tests, and conversations to promote healthy behavior.

Position A: Making birth control pills available over the counter would provide access to contraceptives to women who live in medically under-served places, particularly rural communities. Plus, making birth control over the counter birth would make it more affordable by cutting out insurance companies, easing access to contraceptives for everyone.

Position B: Making birth control available over the counter would likely increase the price of the drug, making it more difficult to access for those who need it most. When Plan B was made available over-the-counter in 2006, its price increased by more than 100 percent, and costs haven't decreased since then. Plus, 89 percent of American women can already access free birth control through insurance.

We recruit a diverse US-based national sample of 3200 respondents using the Lucid survey platform. ${ }^{4}$ Each respondents hears only one of eight potential treatments (the male or female candidate taking one of two sides for each of the four policy debates). This yields 400 respondents per condition, and 800 in each policy area. Respondents first choose which of the two candidates they agree with, and then evaluate the level of expertise they believe each candidate has on the issue under debate based on a 4-point Likert-type scale ranging from "a little" to "a lot." In order to mitigate social desirability bias concerns, we also allow respondents to write an open-ended response to explain their choice. Previous studies indicate that experiments may underestimate actual levels of bias against women in politics due to social desirability bias. Krupnikov et al.

\footnotetext{
${ }^{4}$ Lucid uses sampling quotas to attain a sample that mirrors the US population on the following characteristics: respondent age, gender, race/ethnicity, and region within the USA.
} 
(2016) vary whether respondents choosing between a male and a female candidate were given the opportunity to justify their decision. They find that when respondents were not able to explain their choice, the female candidate won by a large margin. However, when respondents were given the opportunity to explain their vote, the female candidate lost by a significant margin. Therefore, we anticipate that respondents may feel more comfortable disagreeing with the position advocated by the female speaker if they are given the opportunity to justify doing so.

\section{Results}

\subsection{Average treatment effects}

Our main results are presented in Table I. Here we list the percentage of respondents who agree with the male candidate (Brian) or the female candidate (Susan) combined across the two positions the candidate could take. The values thus represent respondents' average level of agreement with Brian or Susan based on hearing the exact same argument. The table also displays the average level of expertise that respondents attribute to Brian and Susan in each policy area on the 4-point scale.

To begin, counter to our expectations, we do not find that respondents are more likely to agree with Brian in what we theorized was a gender-neutral policy area, tourism. Indeed, in this area, we find exactly the opposite: respondents are much more likely to agree with Susan regardless of the position she takes (on average, 57 percent versus 43 percent, $\mathrm{p} \leq 0.001$ ). This is the only policy area where we find significant average treatment effects for the whole group of respondents. We find no differences in respondents' average level of support for either Brian or Susan across the three other policy domains: children's health, birth control access, and national security. We therefore find no support for our hypothesis that respondents would judge the male candidate as more persuasive in the male-stereotyped issue area. We also find no evidence that respondents, in general, find the female candidate more persuasive on issues associated with women (children's health) or pertaining to women's rights (access to birth control). However, our results with regard to perceived expertise stand somewhat in contrast to this finding, as respondents perceive Susan to be significantly more of an expert in health, tourism, and birth control. This is somewhat surprising, as we expected that perceptions of speaker expertise would be tied closely to the persuasiveness of their arguments. We return to this point when discussing the issue of birth control in particular below.

\subsection{Conditional effects by party across policy areas}

We hypothesized that Democrats would tend to agree with Susan on average, whereas Republicans would tend to agree with Brian on average, particularly in gender-congruent policy areas. Table 2 displays conditional average treatment effects by party, which suggest partial support for this hypothesis. Democrats are more likely to agree with Susan on three of the four policy issues (all but health). Republicans are marginally more likely to agree with the stance that Brian takes on the topic of security (by a difference of about 9 percentage points, significant at $p=0.08$ ) and are significantly more likely to agree with Brian's stance on over-the-counter birth control (a difference of 12 percentage points, significant at $\mathrm{p}=0.03$ ).

The policy area in which we observe the largest discrepancy in treatment effects between Democrats and Republicans is on the issue of birth control access. Republicans are significantly more likely to support the position endorsed by Brian, regardless of his stance, and Democrats are significantly more likely to support the position endorsed by Susan, regardless of her stance. Table 2 reveals that in comparison with Brian making the exact same argument, Susan experiences a 18 percentage point bump among Democratic respondents, but a 12 percentage point deficit among Republican respondents. For example, when Susan endorses over-the-counter 
TABLE I. Agreement and perceived expertise by policy area

\begin{tabular}{llllc}
\hline Policy area & Agreement with Susan & Agreement with Brian & Difference & p-value \\
\hline Health & 0.487 & 0.513 & 0.026 & 0.465 \\
Security & 0.512 & 0.488 & 0.024 & 0.480 \\
Tourism & 0.567 & 0.433 & 0.134 & $\leq 0.001$ \\
Birth control & 0.513 & 0.487 & 0.026 & 0.463 \\
\hline & Expertise, Susan & Expertise, Brian & Difference & p-value \\
\hline Health & 2.866 & 2.744 & 0.123 & 0.005 \\
Security & 2.852 & 2.828 & 0.023 & 0.545 \\
Tourism & 3.030 & 2.802 & 0.228 & $\leq 0.001$ \\
Birth control & 3.098 & 2.619 & 0.479 & $\leq 0.001$ \\
\hline
\end{tabular}

Differences significant at $p \leq 0.05$ indicated in bold. $n=3239$.

TABLE 2. Party differences by policy area

\begin{tabular}{|c|c|c|c|c|c|c|}
\hline \multirow[b]{2}{*}{ Policy area } & \multicolumn{3}{|l|}{ Republicans } & \multicolumn{3}{|l|}{ Democrats } \\
\hline & Agreement, Susan & Agreement Brian, & $\mathrm{p}$-value & Agreement, Susan & Agreement, Brian & $\mathrm{p}$-value \\
\hline Health & 0.513 & 0.486 & 0.663 & 0.450 & 0.551 & 0.044 \\
\hline Security & 0.456 & 0.544 & 0.083 & 0.579 & 0.421 & 0.003 \\
\hline Tourism & 0.500 & 0.500 & 1.000 & 0.583 & 0.417 & 0.002 \\
\hline \multirow[t]{2}{*}{ Birth control } & 0.440 & 0.560 & 0.025 & 0.592 & 0.408 & $\leq 0.001$ \\
\hline & Expertise, Susan & Expertise, Brian & $p$-value & Expertise, Susan & Expertise, Brian & $p$-value \\
\hline Health & 2.996 & 2.852 & 0.039 & 2.840 & 2.728 & 0.076 \\
\hline Security & 2.897 & 2.964 & 0.351 & 2.926 & 2.836 & 0.089 \\
\hline Tourism & 3.024 & 2.921 & 0.080 & 3.062 & 2.728 & $\leq 0.001$ \\
\hline Birth control & 3.056 & 2.776 & $\leq 0.001$ & 3.137 & 2.516 & $\leq 0.001$ \\
\hline
\end{tabular}

Differences significant at $p \leq 0.05$ indicated in bold. $n=1031$ Republican and 1182 Democratic respondents.

birth control, Republican support for her stance is 51 percent, but when Brian endorses the same policy, Republican support jumps to 63 percent. The reverse is true for Democrats: support for over-the-counter birth control is 67 percent when Brian endorses it, and climbs to 83 percent when Susan endorses it.

Intriguingly, both Democrats and Republicans tend to rate Susan as substantially more of an expert than Brian on the topic of birth control. Yet, on average, this only translates to support for the position that Susan takes among Democrats. This is, in part, because the average gap in expertise evaluations between Susan and Brian is about twice the size for Democrats than for Republicans. Republicans, on average, rate Susan 0.12 points higher on the 4-point scale, whereas Democrats, on average, rate her 0.29 points higher (difference significant at $p=0.001$ ). Still this does not reveal how individual evaluations of expertise translate to policy support differently for Democrats and Republicans. To do this, Figure 1 plots average support for Susan (combined across the two policies) by the difference in respondents' expertise ratings of the two speakers. The differences are calculated by subtracting a respondent's evaluation of Brian from his or her evaluation of Susan. These values can range from -3 (the respondent rated Susan a 1 and Brian a 4 ) to 3 (the respondent rated Susan a 4 and Brian a 1). Positive values thus indicate the respondent rated Susan as more expert than Brian.

We see that among both Democrats and Republicans, respondents who rated Susan more favorably than Brian are also more likely to agree with the position that she takes. Furthermore, we do not observe significant differences between Democrats and Republicans among respondents who evaluate Brian as having more expertise than Susan on this topic. 
Figure 1. Average agreement with Susan (combined across the two policy areas) by difference in expertise rating (Susan-Brian) for Republican and Democratic respondents. Point sizes reflect the sample size of respondents in each group. Error bars show the standard error of the mean.

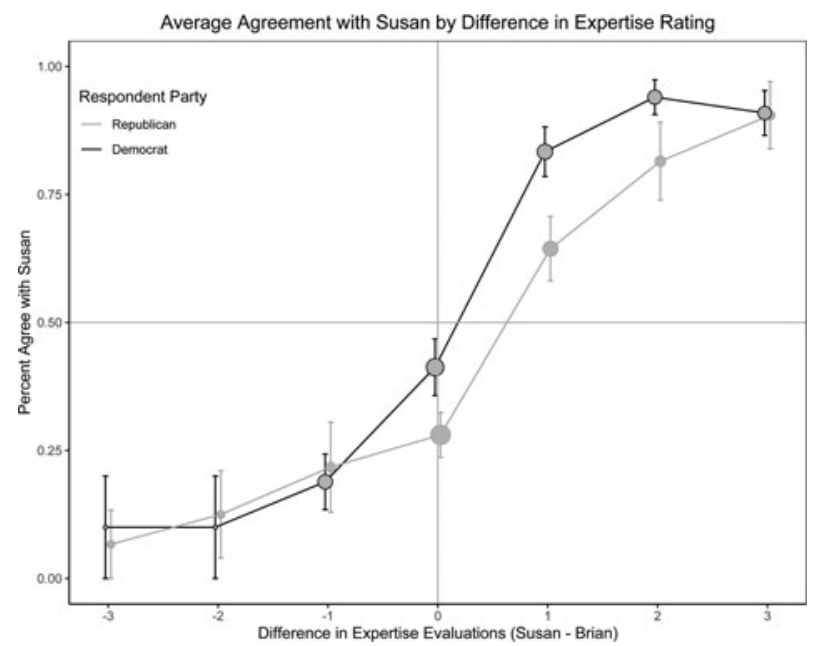

Both Democrats and Republicans in this category are much more likely to agree with Brian's position. Differences by party begin to emerge for respondents who rate Brian and Susan as equally expert. For Democrats in this group, 41 percent agree with Susan whereas only 28 percent of Republicans agree with her in this condition. Partisan differences persist as Susan's evaluations increase relative to Brian. Among respondents who rate her as 1 point higher than Brian, 83 percent of Democrats agree with her position versus 64 percent of Republicans. For respondents who rate Susan as 2 points ahead of Brian, 94 percent of Democrats agree with her, whereas 82 percent of Republicans agree with her in this condition. In sum, although both Democrats and Republicans are more likely to agree with Susan when they believe she is more of an expert than Brian, this association tends to be stronger for Democrats than for Republicans. This is why we observe, on average, that Republicans as a group believe Susan is more of an expert on birth control access, but still tend to agree with whichever stance Brian takes on the issue.

\subsection{Conditional effects by gender and party on birth control access}

To further explore variation among partisans, we next examine differences among male and female respondents within each party on the issue of birth control access. Figure 2 shows average levels of support for over-the-counter birth control when it is endorsed by Brian or Susan among Democratic and Republican men and women, respectively. When Susan takes the ostensibly more liberal position that birth control should be available over the counter, 50 percent of Republican women agree with her; when Brian takes the same position, support among Republican women for the policy increases to 69 percent (difference significant at $\mathrm{p}=0.02$ ). Among Republican men, support for over-the-counter birth control also increases, but less so, moving from 52 to 58 percent when Brian takes this stance $(\mathrm{p}=0.43)$.

Almost the exact reverse is true for Democrats: regardless of the position Susan takes, both men and women are significantly more likely to agree with her than with Brian. When Brian argues for over-the-counter birth control, 74 percent of Democratic men support the policy. When Susan argues for the same policy, support among Democratic men increases to 91 percent (difference significant at $\mathrm{p}=0.005)$. Susan experiences a smaller but still significant bump among Democratic women. Sixty-four percent of Democratic women support over-the-counter birth control when Brian supports it, versus 77 percent when Susan argues for it (difference significant at $p=0.03$ ).

These results suggest differences in effect sizes contingent on respondent gender within both parties, and difference-in-difference tests suggest that these differences in effect size are statistically significant (see Supplementary Appendix Table 4). Republican women increase their support for 


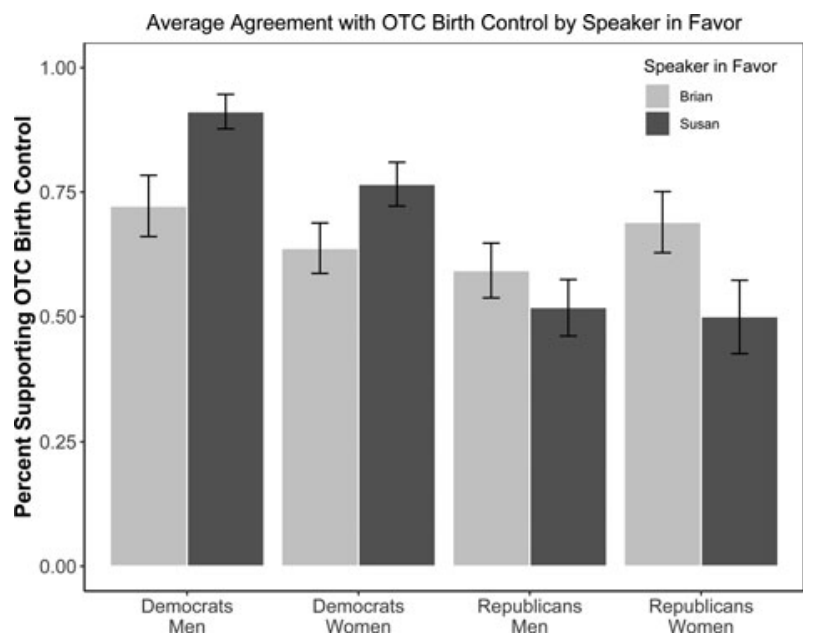

Figure 2. Support for OTC birth control by respondent party and gender, conditional on speaker in favor. Error bars represent standard error of the mean. $n=122$ Democratic men, 185 Democratic women, 162 Republican men, and 106 Republican women.

over-the-counter birth control significantly more than Republican men when the policy is endorsed by Brian rather than Susan $(F$ statistic, $\mathrm{p}=0.006)$. Conversely, Democratic men increase their support for the policy significantly more than Democratic women when it is endorsed by Susan $(F$ statistic, $\mathrm{p} \leq 0.001)$. Put another way, Republican women are the group that is most convinced by Brian and Democratic men are the group that is most convinced by Susan, regardless of the position either speaker takes. ${ }^{5}$

Our results suggest that Democrats-particularly Democratic men-appear to be taking cues on the issue of birth control from Susan, whereas Republicans-particularly Republican womenappear to be taking cues on birth control from Brian. A simple explanation could be that respondents are assuming the candidates represent different parties based on their gender. Yet, there are several reasons why we think this explanation is insufficient. First, our vignettes told respondents multiple times that the candidates were from the same party competing in a state primary election. Still, even if respondents missed this information, partisanship does not appear to be the only factor explaining gender differences in evaluations, as neither Republicans nor Democrats favor one candidate across all policy areas. That is, if partisan respondents were using gender as a cue for which candidate they thought was from their side, we would see Republicans supporting the male candidate and Democrats supporting the female candidate across all four issue areas. Yet, this is not the case. In fact, among Republicans we only see significantly higher levels of support for the male candidate on the issue of birth control. Taken together, these findings suggest our results are not driven by respondents' general allegiance to the candidate they assume is more likely a co-partisan. Rather, there appears to be something specific to the issue of birth control that particularly compels Republicans and Democrats to take opposing cues from the female speaker. This leaves us with a puzzle: why on the issue of birth control specifically, do partisans take such strong and opposing cues from a candidate's gender? This is the only issue for which we see strongly antithetical reactions from different types of voters.

\subsection{Gender and party differences in open-ended responses}

Although our findings are not what we originally expected, we have one additional source of data that allows us to inductively investigate different responses by gender and party on the issue of

\footnotetext{
${ }^{5}$ Among self-identified Independents, we see that women are more likely to support Susan's position and men are more likely to support Brian's position (see Supplementary Appendix 5). This further suggests that on the issue of women's reproductive health, respondent partisanship is a much stronger moderator than respondent gender.
} 
birth control access. Recall that we gave all respondents the option to justify their decision to agree with a particular candidate. Among the 800 respondents who received the birth control policy treatment, we received a total of about 460 open-ended responses from partisans, of which 433 contained substantive content (233 Democrats and 197 Republicans). We code each response across several dimensions, including for key themes as well as general tone. We present full details in Supplementary Appendix 6, but here note differences (or lack thereof) between respondents by gender and party that may provide some descriptive clues to explain our unexpected findings on the topic of birth control access.

To begin, we note that very few respondents (less than 1 percent) explicitly mention the candidate's gender. Many respondents (about 35 percent of the total) articulate an argument made by one of the two candidates that they found particularly compelling (e.g., "I believe it would lower teenage pregnancy.") while most of the remaining responses are too general to classify (e.g., "I believe it should be OTC."). This suggests to us that partisan reactions are largely implicit; they consist of biases or stereotypes that respondents either do not know they have or do not want to admit that they have. Although the number of respondents that mention the speaker directly are small (approximately 14 percent of responses fall under this category), we do code whether these generally reflect a positive or a negative tone. Among these, we do find that Democrats are more likely to express positive affect for Susan than are Republican respondents (47 versus 15 percent, difference significant at $\mathrm{p}=0.006$ ) and more likely to express negative affect for Brian than are Republicans (11 versus 0 percent, difference significant at $p=0.03$ ). Most of the Democrats with affect-tinged responses are expressing a sentiment of greater trust in a woman on this issue (e.g., "She is a female and I'm going to take her side more." and "Why hear a guy? Who the [expletive] is the guy?").

One indicator for which we see significant differences by both party and gender relates to whether the respondent mentions a personal experience in their justification, although the number of responses that fall in this category are small (about 2.5 percent of the total). We observe differences by party: 3.4 percent of Democrats versus 1 percent of Republicans mention a personal experience. Moreover, we see this is driven by Democratic women: 6 percent of Democratic women list a personal experience (e.g., "If I had access to birth control I would have made different decisions." and "I do not have insurance and I would like birth control. I think anyone who needs it should have easy access."), whereas no Democratic men in our sample list a personal experience (difference significant at $\mathrm{p}=0.006$ ). Republican women, for their part, only mention personal experiences in 1.5 percent of their responses. ${ }^{6}$

We are also interested in whether respondent groups found the issue of birth control access more or less salient than other issue areas. We code this in two ways: the percentage of respondents who opted to leave an open-ended response and the average length of response for those who chose to leave one (see Tables 6 and 7 in Supplementary Appendix 6). We do not see consistent differences across issue areas by gender and party in the percentage of respondents who decided to leave an open-ended response. Yet, we do see that when they do decide to leave a response, Republican women leave longer responses on the issue of birth control access than they do on any other issue (18.7 words on average versus 14.5 words, difference significant at $\mathrm{p}=0.01$ ) and more than the other groups of respondents (18.7 words versus 14.4 words, difference significant at $\mathrm{p}=0.01$ ). This is the only issue for which Republican women leave longer responses than the other three respondent groups. That is, if length of response is an indicator, Republican women appear more interested in the issue of birth control more than any other issue and more than any other group of respondents. This suggests to us that the issue of birth control may have evoked particularly strong feelings among Republican women that caused them to pay heightened attention to the speaker's gender. We speculate as to why this might be the case below.

\footnotetext{
${ }^{6}$ This is marginally less than Democratic women, $\mathrm{p}=0.06$, but not significantly less than Republican men who list personal experiences in less than one percent of responses, $\mathrm{p}=0.65$.
} 


\section{Discussion: gender, party, and policy persuasion}

Although our findings related to birth control do not fit our original expectations, we speculate this trend may reflect the very different ways in which a politician's gender serves as a heuristic to men and women of each party. Although the policy debate about over-the-counter birth control is not especially prominent or divisive, reproductive rights are often a contentious topic with clear partisan divides. As such, this issue likely had the most partisan undertones of the four policy areas. More specifically, the topic of access to birth control likely cued some respondents to think about abortion, a topic often highly central to women's political identities (Norrander and Wilcox, 2008, 261). ${ }^{7}$ We did not tell respondents which party the two candidates belonged to, only that they belonged to the same party. Because women's reproductive health is a topic on which Democratic women are more active than Republican women (Swers, 2016), it is possible respondents assumed the two candidates were Democrats. Given that Democratic women tend to be viewed as more liberal than Democratic men particularly on the issue of abortion (Sanbonmatsu and Dolan, 2009, 488), Republican respondents may have assumed the female candidate was more progressive on abortion rights than the male candidate, which may have caused an implicit negative reaction toward her. Moreover, polling data suggest Republican women are both more likely to care about abortion as a political issue and to hold more conservative views on abortion than Republican men (NPR/ PBS NewsHour/Marist Poll, 2019). ${ }^{8}$ This may be why this treatment effect is especially pronounced among Republican women as compared to Republican men.

Notably, our finding regarding Republican women stands in contrast to older research which noted the previous tendency of Republican women to cross party lines to support female candidates (Fox, 1997). Thus, our results may be reflective of a larger sea change in women's political behavior in the United States, with partisanship increasingly eclipsing gender as a determinant of Republican women's political behavior. Partisan polarization has increased precipitously in the American electorate in recent years (Iyengar et al., 2012; Iyengar and Westwood, 2015). Although previous research might have predicted that women would remain more moderate amid increasing polarization-particularly on issues related to women's rights-our results indicate otherwise. Indeed, recent American National Election Studies (2019) data show that polarization between Democratic and Republican women has kept up with or even outpaced polarization between non-co-partisan men, as measured by respondents' strength of identification with their own party and feelings toward the other major party. Moreover, although women in the US House of Representatives historically have been more moderate than their male colleagues and more likely to support women's rights issues (Swers, 1998), women elected in recent years hold ideological stances increasingly similar to their male co-partisans (Frederick, 2009; Shames, 2018), and women in Congress have become less likely to engage in bipartisan collaboration over time (Lawless et al., 2018).

Our finding that Democratic men are more likely than Democratic women to agree with the female candidate was also counter to our original expectations. We speculate this find may be because gender serves as a more powerful heuristic for men than for women, particularly among Democrats. By definition, women are more likely to have direct experience with a form of birth control that is taken exclusively by women. Because of this, women's attitudes may be more fixed on this topic. Men, on the other hand, likely have less crystallized opinions on this issue and may rely on the female speaker to a greater degree than women in order to make the "right" policy choice (for similar perspectives, see Mansbridge, 1999; Clayton et al., 2019). Recall that we found some evidence in support

\footnotetext{
${ }^{7}$ We also code whether respondents make reference to the issue of abortion (e.g., note they are "pro-choice" or "pro-life" or mention abortion explicitly) when discussing women's health care (about 5 percent of responses fall into this category). We do not see systematic differences by gender or party in the frequency of these responses.

${ }^{8}$ A 2019 NPR/PBS NewsHour/Marist Poll finds that 18 percent of Republican women stated abortion was the most important issue for them in the 2020 election compared to 13 percent of Republican men. Moreover, 68 percent of Republican women identify as pro-life (with only 3 percent reporting that they are unsure of their position), whereas only 59 percent of Republican men state they are pro-life (with 11 percent stating they are unsure of their position).
} 
of this interpretation from the open-ended responses. Slightly over five percent of Democratic women respondents cited personal experiences in their justification of the position that they took, whereas not a single Democratic man did. Of course, this almost certainly underestimates the number of women in our survey who have had direct experience seeking oral contraception.

Finally, our findings also contribute to the literature on persuasion more broadly. Previous research generally suggests that a speaker who appears to have more expertise on an issue should be more persuasive than a speaker who appears to have less expertise (Pornpitakpan, 2004). We expected respondents' perceptions of expertise to weigh heavily in their evaluations of technically detailed policy debates, such as on over-the-counter birth control. Instead, we found that perceptions of expertise are not necessarily associated with greater persuasiveness, on average. Most notably, although on average Republican respondents did report that the female candidate was more of an expert on the issue of birth control, they still tended to favor the position advocated by the male candidate. It appears that seeing a woman as expert in a policy area does not necessarily lead voters to agree with the position that she takes (cf. Dolan, 2010). Our findings thus suggest that politics is likely an arena in which voters' perceptions of expertise are less important than other characteristics of the speaker.

Our results were unexpected and our interpretations are thus necessarily speculative. Future research might test the theoretical implications that arise from our results more directly. For example, we speculate that men have less crystallized views on the issue of women's reproductive health, but future experimental study might capture this through specific pre-treatment measures of opinion crystallization. Future research might also make partisanship explicit in order to test whether Republican women equally penalize a female candidate on the issue of women's reproductive health when they are told the candidate is a Republican. As they stand, our results suggest that Republican women feel the least satisfied with the opinions expressed by female candidates on the issue of women's reproductive rights. Making partisanship explicit would allow future research to test the extent to which Democratic and Republican women feel they are substantively and symbolically represented by female politicians. Finally, future research could consider other issues related to women's rights (e.g., pay equity, violence against women, etc.) to see if these results hold outside of reproductive rights. This line of inquiry is particularly topical given how salient women's rights are in the current national discourse, as issues related to sexual harassment and assault and access to reproductive health care are subject to intense partisan debate and a rapidly shifting legal landscape.

Supplementary material. The supplementary material for this article can be found at https://oi.org/10.1017/psrm.2021.4.

\section{References}

American National Election Studies (2019) 2019 Pilot Study. Available at https://electionstudies.org/data-center/2019-pilotstudy/

Bauer NM (2020) The Qualifications Gap: Why Women Must be Better Than Men to Win Political Office. New York: Cambridge University Press.

Beckwith K (2014) Plotting the path from one to the other: women's interests and political representation. In Escobar-Lemmon MC and Taylor-Robinson MM (eds), Representation: The Case of Women. New York: Oxford University Press, pp. 19-40.

Cassese EC and Holman MR (2018) Party and gender stereotypes in campaign attacks. Political Behavior 40, $785-807$.

Clayton A, Josefsson C and Wang V (2014) Present without presence? Gender, quotas and debate recognition in the Ugandan parliament. Representation 50, 379-392.

Clayton A, O'Brien DZ and Piscopo JM (2019) All male panels? Representation and democratic legitimacy. American Journal of Political Science 63, 113-129.

Ditonto TM, Hamilton AJ and Redlawsk DP (2014) Gender stereotypes, information search, and voting behavior in political campaigns. Political Behavior 36, 335-358.

Dolan K (2004) Voting for Women: How the Public Evaluates Women Candidates. New York: Westview Press.

Dolan K (2010) The impact of gender stereotyped evaluations on support for women candidates. Political Behavior 32, 69-88.

Druckman JN and Lupia A (2016) Preference change in competitive political environments. Annual Review of Political Science 19, 13-31.

Eagly AH and Karau SJ (2002) Role congruity theory of prejudice toward female leaders. Psychological Review 109, 573-598.

Escobar-Lemmon M and Taylor-Robinson MM (2005) Women ministers in Latin American Government: when, where, and why? American Journal of Political Science 49, 829-844. 
Fox R (1997) Gender Dynamics in Congressional Elections. Thousand Oaks, CA: Sage Publishers.

Frederick B (2009) Are female house members still more liberal in a polarized era? The conditional nature of the relationship between descriptive and substantive representation. Congress \& the Presidency 36, 181-202.

Hayes D (2011) When gender and party collide: stereotyping in candidate trait attribution. Politics and Gender 7, $133-165$.

Heilman ME (2012) Gender stereotypes and workplace bias. Research in Organizational Behavior 32, 113-135.

Heilman ME and Haynes MC (2005) No credit where credit is due: attributional rationalization of women's success in malefemale teams. Journal of Applied Psychology 90, 905-916.

Holman MR, Merolla JL and Zechmeister EJ (2016) Terrorist threat, male stereotypes, and candidate evaluations. Political Research Quarterly 69, 134-147.

Huddy L and Terkildsen N (1993) Gender stereotypes and the perception of male and female candidates. American Journal of Political Science 37, 119-147.

Iyengar S and Westwood SJ (2015) Fear and loathing across party lines: new evidence on group polarization. American Journal of Political Science 59, 690-707.

Iyengar S, Valentino N, Ansolabehere S and Simon AF (1997) Running as a woman: gender stereotyping in women's campaigns. In Norris P (ed.), Women in Media and Politics, Oxford: Oxford University Press, pp. 77-98.

Iyengar S, Sood G and Lelkes Y (2012) Affect, not ideology: a social identity perspective on polarization. The Public Opinion Quarterly 76, 405-431.

Kahn KF (1994) The distorted mirror: press coverage of women candidates for statewide office. Journal of Politics 56, $154-173$.

Karpowitz CF, Mendelberg T and Shaker L (2012) Gender inequality in deliberative participation. American Political Science Review 106, 533-547.

Klar S (2018) When common identities decrease trust: an experimental study of partisan women. American Journal of Political Science 62, 610-622.

Koch J (2000) Do citizens apply gender stereotypes to infer candidates ideological orientations?. The Journal of Politics 62, 414-429.

Krook ML and O'Brien DZ (2012) All the president's men? The appointment of female cabinet ministers worldwide. Journal of Politics 74, 840-855.

Krupnikov Y and Bauer NM (2014) The relationship between campaign negativity, gender and campaign context. Political Behavior 36, 167-188.

Krupnikov Y, Piston S and Bauer N (2016) Saving face: identifying voter responses to black candidates and female candidates. Political Psychology 37, 253-273.

Lasswell H (1948) Power and Personality. New York: W W Norton \& Co.

Lawless JL, Theriault SM and Guthrie S (2018) Nice girls? Sex, collegiality, and bipartisan cooperation in the US congress. The Journal of Politics 80, 000-000.

Madsen JK (2019) Voter reasoning bias when evaluating statements from female and male political candidates. Politics \& Gender 15, 310-335.

Mansbridge J (1999) Should blacks represent blacks and women represent women? A contingent "yes". The Journal of Politics 61, 628-657.

Meeks L and Domke D (2016) When politics is a woman's game: party and gender ownership in woman-versus-woman elections. Communication Research 43, 895-921.

Mendelberg T, Karpowitz CF and Oliphant JB (2014) Gender inequality in deliberation: unpacking the black box of interaction. Perspectives on Politics 12, 18-44.

Norrander B and Wilcox C (2008) The gender gap in ideology. Political Behavior 30, 503-523.

NPR/PBS NewsHour/Marist Poll (2019) Available at http://maristpoll.marist.edu/wp-content/uploads/2019/06/NPR_PBSNewsHour_Marist-Poll_USA-NOS-and-Tables-on-Abortion_1906051428_FINAL.pdf\#page=3

Pornpitakpan C (2004) The persuasiveness of source credibility: a critical review of five decade's evidence. Journal of Applied Social Psychology 34, 243-281.

Sanbonmatsu K and Dolan K (2009) Do gender stereotypes transcend party? Political Research Quarterly 62, $485-494$.

Searles K, Fowler EF, Ridout TN, Strach P and Zuber K (2017) The effects of men's and women's voices in political advertising. Journal of Political Marketing, 1-29.

Shames SL (2018) Higher hurdles for republican women: ideology, inattention, and infrastructure. In Och M and Shames SL (eds). The Right Women: Republican Party Activists, Candidates, and Legislators. Santa Barbara, CA: Praeger, pp. 95-106.

Swers ML (1998) Are women more likely to vote for women's issue bills than their male colleagues? Legislative Studies Quarterly 23, 435-448.

Swers ML (2016) Pursuing women's interests in partisan times: explaining gender differences in legislative activity on health, education, and women's health issues. Journal of Women, Politics \& Policy 37, 249-273.

Volden C, Wiseman AE and Wittmer DE (2013) When are women more effective lawmakers than men? American Journal of Political Science 57, 326-341.

Cite this article: Anderson-Nilsson G, Clayton A (2021). Gender and policy persuasion. Political Science Research and Methods 9, 818-831. https://doi.org/10.1017/psrm.2021.4 